Proc. XIX International School of Semiconducting Compounds, Jaszowiec 1990

\title{
METHOD OF DETERMINATION OF Mn CONCENTRATION IN ZnS BASED ON KINETIC MEASUREMENTS OF LUMINESCENCE*
}

\author{
E. Chimczak, M. Bertrandt-ŻYTkowiak \\ Institute of Physics, Poznań Technical University, Piotrowo 3, 60-965 Poznań, Poland \\ (Received August 8, 1990)
}

\begin{abstract}
A method of determination of Mn concentration in ZnS:Mn based on existence of two manganese kinetic components is proposed. In the method the manganese concentration is determined by lifetime and initial intensity of electroluminescence measurements. The results of the measurements are compared with statistical distributions of single $\mathrm{Mn}^{2+}$ ions and $\mathrm{Mn}^{2+}-\mathrm{Mn}^{2+}$ pairs in hexagonal $\mathrm{ZnS}$.
\end{abstract}

PACS numbers: 78.60.Fi

\section{Introduction}

Information about the dopant concentrations are very important in the field of semiconductor investigations. In many papers concentration dependences of various magnitudes are shown. In luminescence, for example, a lifetime dependence on dopant concentration is often measured [1-10]. This dependence can be used for determinaton of the dopant concentration. There are some propositions of concentration determination by optical measurements [10-12]. In the paper we propose another optical method of determination of Mn concentration in ZnS:Mn.

\section{Description of the method}

Let us assume that an activator (i.e. a dopant) creates two different kinds of monomolecular luminescent centres. Then decay curve of luminescence can be written as

$$
I=I_{01} \exp \left(-t / \tau_{1}\right)+I_{02} \exp \left(-t / \tau_{2}\right)
$$

*This work was supported by CPBP 01.06.11.04. 


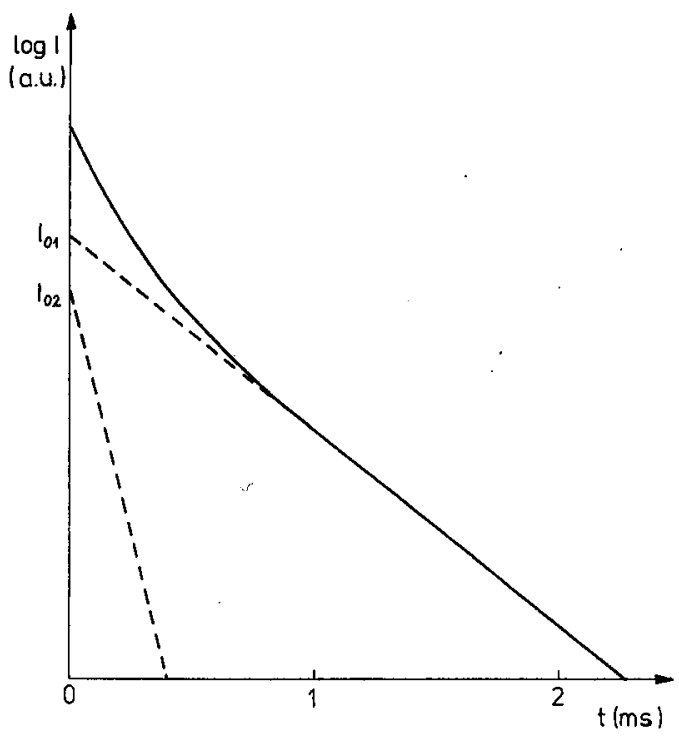

Fig. 1. Decay curve of luminescence in semilogarithmic scale (solid line) and its exponential components (dashed lines).

where $I_{0}$ is the initial intensity of luminescence and $r$ is the lifetime of luminescent centre, 1 and 2 are due to both kinds of the luminescent centres (we assume that the radiative decay of the excited centres is the dominant one). In the semilogarithmic scale, the curve can be plotted as two straight lines resulting from the presence of these two centres (Fig. 1). For a monomolecular centre, we can write

$$
I_{0}=\frac{N_{0}^{*}}{\tau}
$$

where $N_{0}^{*}$ is the initial number of excited centres. For both kinds of the centres, we can obtain

$$
\frac{N_{01}^{*}}{N_{02}^{*}}=\frac{I_{01} \tau_{1}}{I_{02} \tau_{2}}
$$

Assuming that the number of excited centres is proportional to the number of all the same centres in luminophor, we have

$$
\frac{N_{01}^{*}}{N_{02}^{*}}=\frac{N_{1}}{N_{2}}
$$

It is possible to calculate theoretically probability $p$ of finding a given kind of luminescent centres for various concentration $[13,14]$. Taking into account that

$$
\frac{p_{1}}{p_{2}}=\frac{N_{1}}{N_{2}}
$$


we obtain the following relation.

$$
\frac{p_{1}}{p_{2}}=\frac{I_{01} \tau_{1}}{I_{02} \tau_{2}}
$$

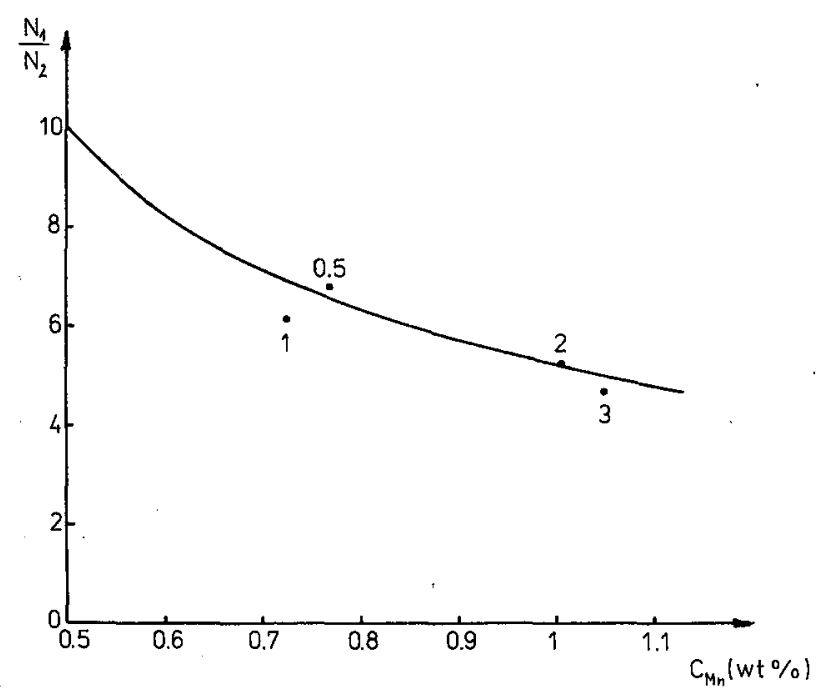

Fig. 2. Ratio of number of single $\mathrm{Mn}^{2+}$ centres and $\mathrm{Mn}^{2+}-\mathrm{Mn}^{2+}$ pairs versus $\mathrm{Mn}$ concentration in $\mathrm{ZnS}$ : theoretical curve (solid line) and experiment (points); 0.5, 1, 2, $3 \mathrm{wt} \% \mathrm{Mn}$ concentration in powdered $\mathrm{ZnS}$ used to evaporation of the films.

\section{Results and discussion}

It is well-known that, generally, manganese in $\mathrm{ZnS}$ creates two kind of centres: $\mathrm{Mn}^{2+}$ ions and $\mathrm{Mn}^{2+}-\mathrm{Mn}^{2+}$ pairs $[2,3,7,15]$. So, we can use the above described method to determine concentration of manganese in our electroluminescent thin film cells. The preparation of the cells was described in [16, 17]. In order to determine the Mn concentration in the cells investigated, we used $\tau_{1}$ the lifetime dependence on $\mathrm{Mn}^{2+}$ concentration introduced by Vlasenko et al. [2]. Figure 2 shows a comparison of the method described in Sec. 2 with the experiment. The solid curve represents ratio of probability of appearance of single $\mathrm{Mn}^{2+}$ ions and $\mathrm{Mn}^{2+}-\mathrm{Mn}^{2+}$ pairs calculated from statistical distributions obtained by Behringer [13] for the hexagonal structure of $\mathrm{ZnS}$ matrix. As it is seen in the figure, we have obtained a satisfactory accordance between model and the experiment except point $1(1 \mathrm{wt} \%)$. We have not obtained a good agreement using the other data (on $\tau_{1}$ vs. $\mathrm{Mn}^{2+}$ concentration) [1,3-10]. Our result points out that the proposed method can be applied only when both kinds of manganese centres are excited 
identically. The condition is not always fulfiled. Probability of excitation of each kind of manganese centres depends, for example, on level of excitation [18]. The method can not be also used when one kind of manganese centres are favoured during the excitation [3]. Experimental points lie over the theoretical curve when single $\mathrm{Mn}^{2+}$ centres are favoured and the points lie under the curve in the opposite case. In summary, the new method of determining a concentration of the dopant exhibiting two species has been proposed. We have illustrated its applicability to the situation of $\mathrm{Mn}^{2+}$ ions and $\mathrm{Mn}^{2+}-\mathrm{Mn}^{2+}$ pairs in $\mathrm{ZnS}$ semiconductor.

\section{References}

[1] B. Selle, Phys. Status Solidi 5, 649 (1964).

[2] N.A. Vlasenko, S.A. Zynio, Yu.V. Kopytko, Phys. Stalus Solidi A 29, $671(1975)$.

[3] W. Busse, H.-E. Gumlich, B. Meissner, D. Theis, J. Lumin. 12/13, 693 (1976).

[4] J.M. Hurd, C.N. King, J. Electron. Mater. 8, 879 (1979).

[5] M.S. Skolnick, J. Phys. D 14, 301 (1981).

[6] H. Sasakura, H. Kobayashi, S. Tanaka, J. Mita, T. Tanaka, J. Lumin. 24/25, 897 (1981).

[7] P.J. Wright, B. Cockayne, A.F. Cattel, P.J. Dean, A.D. Pitt, G.W. Blackmore, J. Crystal Growth 59, 155 (1982).

[8] N.A. Vlasenko, Yu.V. Kopytko, V.S. Pekar, Phys. Status Solidi A 81, 661 (1984).

[9] Dang Dinh Thong, W. Heimbrodt, D. Hommel, O. Goede, Phys. Status Solidi A 81, 695 (1984).

[10] R. Mach, J. von Kalben, W. Gericke, G.O. Muller, G.U. Reinsperges, Phys. Status Solidi A 75, 489 (1983).

[11] O. Goede, W. Heimbrodt, T. Lau, G. Matzkeit, B. Selle, Phys. Status Solidi $A$ 94, 259 (1986).

[12] R. Mach, W. Gericke, H. Treptov, W. Ludwig, Phys. Status Solidi A 49, 667 (1978).

[13] R.E. Behringer, J. Chem. Phys. 29, 537 (1958).

[14] M.M. Kreitman, D.L. Barnett, J. Chem. Phys. 43, 364 (1965).

[15] E. Walentynowicz, E. Chimczak, W. Gordon, J. Lumin. 17, 109 (1978).

[16] E. Chimczak, R. Czajka, M. Bertrandt-Żytkowiak, W.S. Gordon, Thin Solid Films 76, 349 (1981).

[17] E. Chimczak, M. Bertrandt-Żytkowiak, W.S. Gordon, J. Lumin. 35, 111 (1986).

[18] R. Tornqvist, M. Ylilammi, J. Lumin. 27, 285 (1982). 